\title{
What Influences the Sustainable Food Consumption Behaviours of University Students? A Systematic Review
}

\begin{abstract}
Lucía Aguirre Sánchez ${ }^{1,2 *}$, Zayne M. Roa-Díaz ${ }^{3,4}$, Magda Gamba ${ }^{3,4}$, Giorgia Grisotto ${ }^{3,4,5}$, Ana Maria Moreno Londoño ${ }^{6}$, Blanca Patricia Mantilla-Uribe ${ }^{7}$, Alba Yaneth Rincón Méndez ${ }^{7}$, Mónica Ballesteros ${ }^{8}$, Doris Kopp-Heim ${ }^{9}$, Beatrice Minder ${ }^{9}$, L. Suzanne Suggs ${ }^{1,2,10}$ and Oscar H. Franco $3,5,10$
\end{abstract}

\begin{abstract}
${ }^{1}$ Institute of Public Health (IPH), Università della Svizzera italiana, Lugano, Switzerland, ${ }^{2}$ Institute of Communication and Public Policy (ICPP), Università della Svizzera italiana, Lugano, Switzerland, ${ }^{3}$ Institute of Social and Preventive Medicine (ISPM), University of Bern, Bem, Switzerland, ${ }^{4}$ Graduate School for Health Sciences, University of Bern, Bern, Switzerland, ${ }^{5}$ Harvard T.H. Chan School of Public Health, Boston, MA, United States, ${ }^{6}$ Independent Researcher, Lugano, Switzerland, ${ }^{7}$ Instituto Proinapsa, Universidad Industrial de Santander, Bucaramanga, Colombia, ${ }^{8}$ Centro de Investigación Biomédica en Epidemiología y Red de Salud Pública, Instituto de Salud Carlos III (ISCIII), Madrid, Spain, ${ }^{9}$ Public Health and Primary Care Library, University of Bern, Bern, Switzerland, ${ }^{10}$ Swiss School of Public Health (SSPH+), Zurich, Switzerland
\end{abstract}

Objectives: Global environmental challenges demand sustainable behaviours and policies to protect human and planetary health. We aimed to summarize the evidence about the factors related to Sustainable Food Consumption (SFC) behaviours of university students, and to propose an operational categorization of SFC behaviours.

Methods: Seven databases were searched for observational studies evaluating Sustainable Food Consumption (SFC) among university students and that reported at

OPEN ACCESS

Edited by: Karin De Ridder

Sciensano, Belgium

*Correspondence:

Lucía Aguirre Sánchez lucia.aguirre.sanchez@usi.ch

This Review is part of the IJPH Special Issue "Food as a Public Health Issue"

Received: 09 April 2021 Accepted: 17 August 2021 Published: 07 September 2021

Citation:

Aguirre Sánchez L, Roa-Díaz ZM, Gamba M, Grisotto G, Moreno Londoño AM,

Mantilla-Uribe BP, Rincón Méndez $A Y$, Ballesteros M, Kopp-Heim D, Minder B, Suggs LS and Franco $\mathrm{OH}$ (2021) What Influences the Sustainable

Food Consumption Behaviours of University Students? A Systematic Review. Int J Public Health 66:1604149. doi: 10.3389/ijph.2021.1604149 least one behavioural outcome measure. Qualitative synthesis was conducted, and PRISMA guidelines for reporting were followed.

Results: Out of 4,479 unique references identified, 40 studies were selected. All studies examined personal factors, while 11 out of 40 also measured social or situational factors. Except for food waste, females had higher levels of SFC behaviours, but situational factors moderated this association. Knowledge and attitudes showed mixed results. Overall, sustainable food consumers reported healthier lifestyles.

Conclusions: Healthy lifestyle of sustainable food consumers suggests possible synergies between human health and sustainability in terms of motivations for food choice. Moderation effects of social and situational factors on personal factors reveal opportunities to design and examine the effects of choice architecture interventions.

\footnotetext{
Keywords: sustainable food consumption, sustainable diets, pro-environmental behaviour, health behaviour, university students, young adults, young people, systematic review
}

\section{INTRODUCTION}

Food connects human and planetary health. Diet-related factors are among the top contributors to the global burden of disease [1], and the food sector is the leading cause of environmental change, contributing to $19-29 \%$ of the global Greenhouse gas (GHG) emissions [2]. Climate change drives adverse effects back into human health [3], affecting food availability, the nutritional contents of foods, and putting populations at risk of nutritional deficiencies [4]. 
FAO defines sustainable diets as those with "low environmental impacts which contribute to food and nutrition security and to healthy life for present and future generations [...]" [5], in line with earlier definitions of sustainable consumption [6]. The EAT-Lancet Commission proposes a healthy diet from sustainable food systems [3], identifying three main spheres for food system transformation: improvements in production, widespread change in dietary patterns, and waste reduction. However, to date, there is no operational and widely accepted definition of sustainable food consumption behaviours, and the factors associated remain unclear.

While health and environmental co-benefits of sustainable diets have been reported in the literature [7-10], from the consumer perspective, sustainable food consumption may pose a tension between individual and collective interests, adding a pro-social aspect to food consumption. Therefore, behavioural approaches are needed to understand what drives the adoption of healthier and more sustainable eating behaviours, especially those with lower environmental impact [3,11]. However, research about behavioural aspects of sustainable food consumption is considered scarce compared to the extensive body of evidence on the adverse environmental and health impact of eating behaviours [12-14].

University students, in particular, are more willing to adopt changes in their eating behaviours, and are more environmentally conscious than older generations [15]. Universities are the organizations where studies on behaviour and consumption are most frequently conducted, with estimations of up to $80 \%$ of the literature in this field is based on student samples [16].

University students engage in unhealthy eating behaviours [17], which has yielded a vast body of literature on the importance of healthy diets among this population. The adherence to food consumption behaviours that are healthy and also sustainable has gained some attention [18-20]. Hence, we aimed to systematically summarize the evidence regarding the underlying factors that can determine or constrain sustainable food consumption among university students and propose an operational categorization of Sustainable Food Consumption (SFC) behaviours.

\section{METHODS}

This systematic review was conducted following the guide proposed by Muka and colleagues [21] and the PRISMA guidelines for reporting [22]. The protocol is registered in PROSPERO: CRD42021233347.

\section{Data Source and Search Strategy}

The search strategy (See search strategies in Supplementary Material) was developed by the authors, including two librarians. The search was limited to human studies and peerreview publications. The search terms included synonyms of sustainable food consumption and specific behaviours based on relevant literature, on diets and food systems with lower environmental impact [3, 23]. Medline, Embase, PsycInfo,
Web of Science, Scopus, LILACS databases and Google Scholar were searched to identify relevant articles from inception until 27 January 2021 without language or geographic restrictions $[3,23,24]$. Backward reference search was conducted on each of the studies selected from the database search. Expert input and a manual search in relevant journals were also used (See Search Strategies in Supplementary Material).

\section{Selection Criteria}

Studies were included if they: were conducted with university students; were observational (e.g., cross-sectional); presented behavioural outcome measures of SFC, and identified factors associated with SFC. Our operational definition of Sustainable Food Consumption includes both dietary patterns and other consumer behaviours related to how food is produced, processed, transported, managed and wasted. Building on Garnett et al 2014 [23], the outcome also includes behaviours such as choosing foods with less energy-intensive transport modes, such as local and seasonal products, meat eaten in moderate quantities, dairy products or alternatives eaten in moderation, and tap water in preference to other beverages.

Studies were excluded if participants reported comorbidities or were post-doctoral researchers, evaluated the efficacy or effectiveness of interventions focused on farming, agriculture, or other food production-related behaviours, or assessed behavioural intentions, attitudes, and willingness but not actual behaviours. Cost-effectiveness studies, case reports, letters to the editor, conference proceedings, systematic reviews, or meta-analyses were also excluded.

\section{Screening and Study Selection}

Pairs of screeners independently reviewed titles and abstracts of the retrieved references. Overlapping references were included for full-text screening. Inclusion disagreements were solved initially by the reviewers and persistent disagreements were solved upon consultation with a third reviewer.

\section{Data Analysis and Synthesis of Results}

A tailored data extraction form was developed and piloted for this study. The form included identifiers, general characteristics of the study and participants, and results (See Supplementary Material). Qualitative analysis of the reviewed articles was conducted following deductive categorization of behavioural outcomes, data reduction, and narrative synthesis of related factors, as associations, correlations and descriptive group comparisons. The proposed behavioural categories were built deductively from relevant literature, while the target behaviours were extracted from the measurement instruments reported in selected articles. Given the diversity of measurement approaches, quantitative meta-analysis was not performed.

\section{Quality Assessment}

Two reviewers independently assessed the quality of included studies using the Newcastle-Ottawa Scale [25] (NOS) for crosssectional studies; disagreements were solved by consensus. NOS was developed for non-randomized and observational studies and 


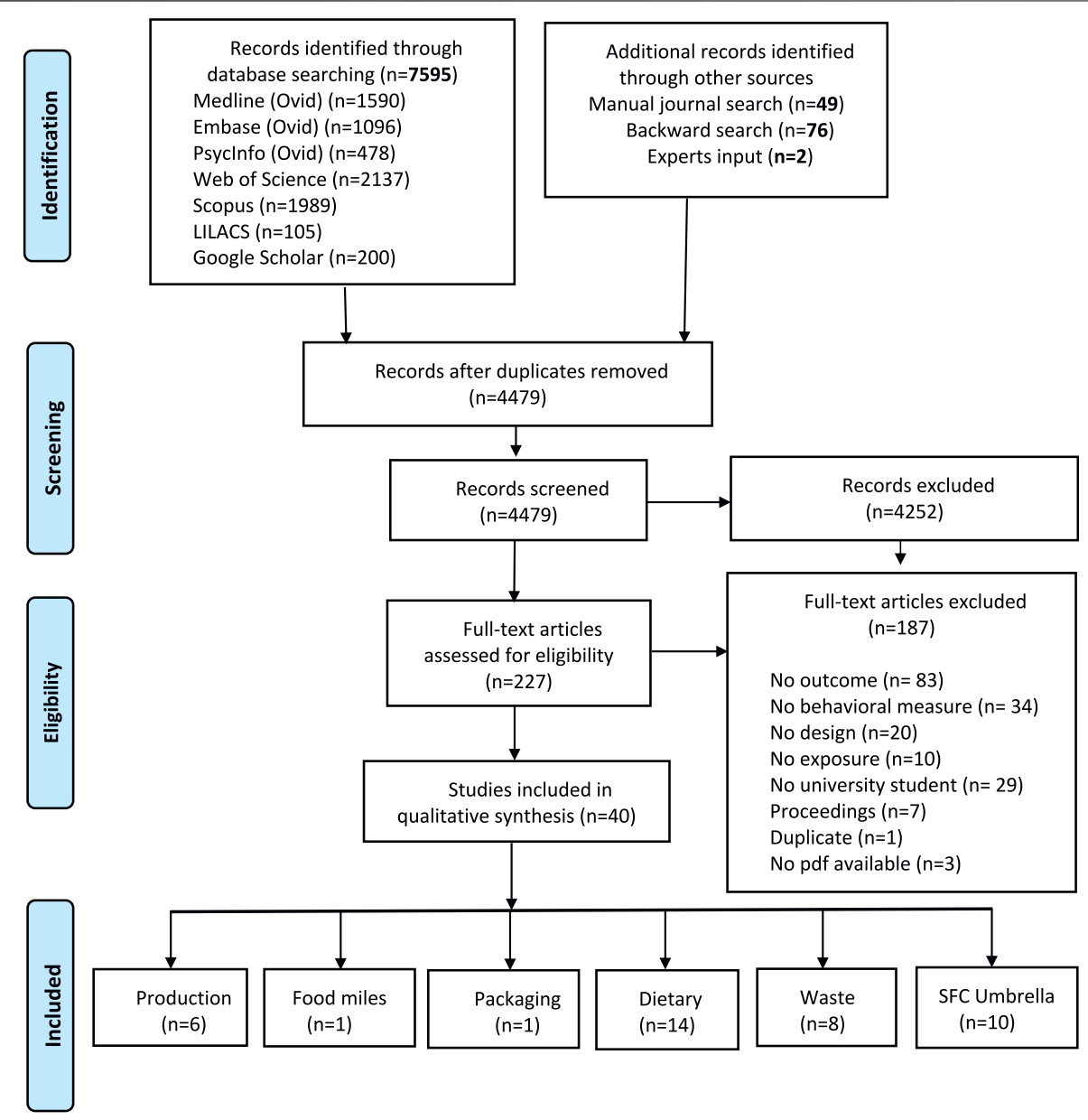

FIGURE 1 | Preferred Reporting Items for Systematic reviews and Meta-Analyses (PRISMA) flowchart for selected articles. (What influences the sustainable food consumption behaviours of university students? A systematic review, several countries, 2021).

assessed quality in three broad categories: selection of study groups/participants, comparability of the study groups/ participants, and the assessment of outcome of interest. Quality was assessed on a 10-point scale and classified as good (10-9 points), moderate (8-6 points), and low quality ( $\leq 5$ points). All studies were included in the analysis, independently of NOS score.

\section{RESULTS}

\section{Study Selection}

We identified 4,479 unique references, of which 227 were selected to be screened in full text. Of those, 40 studies comprising 27,946 participants met the selection criteria (See Figure 1). A summary of included papers is presented in Table $\mathbf{1}$.

\section{Study Population and Measurement}

There were four multi-country studies [26-29] and in total 30 represented countries. The top frequencies of study locations were 10 from the United States (US) [30-39], five from Italy [40-44], and three from Spain [45-47]. All the included papers were cross- sectional and were based on 38 unique samples. Ten articles addressed an umbrella concept (e.g., sustainable, green or climate-friendly food consumption) and measured several target behaviours [31, 37, 43, 48-54], while the rest reported a single outcome relevant for the analysis. Almost a third of the articles adopted a specific theoretical or conceptual framework for hypothesis formation and measurement. The most common was the Theory of Planned Behaviour (TPB) [28, 41, 54-56]. All the 40 studies identified evaluated personal factors while 11 (29\%) also included social or situational factors. Being a woman was reported as a factor related to SFC in eight out of the twelve articles that reported significant gender-related differences. Three reported lower levels of food waste in men. The mean age of the study participants ranged from 18 to 29 years. On average, $60.7 \%$ were women and two studies were conducted with female students only.

\section{Behavioural Categories of Sustainable Food Consumption (SFC)}

This section summarizes the findings about factors related to the observed sustainable, and unsustainable, food consumption 
TABLE 1 | Articles included in the review. (What Influences the Sustainable Food Consumption Behaviours of University Students? A Systematic Review, Several countries, 2021).

\begin{tabular}{|c|c|c|c|}
\hline $\begin{array}{l}\text { Author, year, } \\
\text { country }\end{array}$ & $\begin{array}{c}\mathrm{n}^{\mathrm{a}},(\% \\
\text { of women), } \\
\text { age }\end{array}$ & Behavioural outcome & $\begin{array}{l}\text { Examined factors } \\
\text { (in addition } \\
\text { to demographics }{ }^{b} \text { ) }\end{array}$ \\
\hline
\end{tabular}

Akbar et al., 2019, $\quad n=221$, (33.5), NR Organic Food Buying

Pakistan

Dahm et al., 2009,

$n=443,(55.8), M=$ 21.6, SD 5.01

Organic food consumption United States and purchase

Giampietri et al. 2020., Italy

$n=223,(47.1), M=$ 22.45 SD 2.5

Hamilton and Hekmat, $\quad n=426$, (NR), NR 2018, Canada

Organic food consumption

Organic food consumption

Green Perceived Value (GPV) constructs (functional value, social value, emotional value, and conditional value), purchase intention, food neophobia.

McReynolds et al., 2017., United States
Organic food consumption and purchase

Organic food consumption

\begin{abstract}
Zámková and M.
Prokop, 2013, Czech
\end{abstract} Republic $n=238,(40), M=$ 22.4 SD 6.5

NR

$$
\begin{array}{cl}
n=195,(55.4), M= & \text { Locally produced food } \\
21.34 \text { SD Not } & \text { products } \\
\text { applicable } &
\end{array}
$$

Fernandez-Ferrin et al., 2017, Spain
Local identity, brand valuation, and moderating effect of perceived availability.

Perceptions about bottled and tap water. water consumption frequency
Spain

Barros et al., 2020,

Brazil

Forestell et al., 2012, $\quad n=240$, (100), $\mathrm{M}=$ United States
19.28
Awareness (knowledge) and attitudes toward organic foods, and attitudes and behaviours regarding other ecofriendly practices.

Individual risk attitude isk attitude Knowledge and attitudes. nowledge and perceptions about organic food, demographic and socioeconomic characteristics

Exposure to organic food advertisement.
Attitude predicted purchase and consumption of organic foods on campus.

More risk averse individuals eat organic food frequently. Trust and social norms were linked to organic food consumption.

Attitudes (safety of organic food, the Low nutrition value of organic food, the perception that organic food is fresher and better in taste and the perception that organic food is better for animal welfare and the environment) were significantly associated with the frequency of consumption. Perceived safety was highly correlated with organic food consumption.

There was a significant correlation between students' knowledge and behaviour. Having experience growing fruits or vegetables had the greatest impact.

Women bought organic food more frequently than men. Main reason of disinterest in buying organic is the price, distrust and not believing that organic food is better than conventional food. Advertising for organic food did not affect purchase. Perceived availability condition the promoting effect of local identity on purchase of local tomato sauce and local rice. Perceived availability does not moderate purchase of local mineral water and traditional cake. Students presented the highest proportions of consumption of more than 6 bottles of water per week. Beliefs (e.g., "I trust tap water's quality," "If I drink tap water, I am contributing less plastic to landfills") had statistical differences between low consumption group ( 0 bottles per week) and high bottled water users ( $\geq 6$ bottles per week). No associations with gender. Males had less odds of being vegetarians. Those who reported prejudicial alcohol use were almost twice as likely to adopt a vegetarian diet.

Food restraint, lifestyle (e.g., drinking alcohol, smoking), personality inventory, variety seeking, food neophobia, general neophobia, food choice, sensory appeal, price,
Vegetarians and pesco-vegetarians were more open to new experiences, variety seeking, and less food neophobic than regular omnivores. Semi-vegetarians and flexitarians were more restrained than omnivores. (Continued on following page) 
TABLE 1 | (Continued) Articles included in the review. (What Influences the Sustainable Food Consumption Behaviours of University Students? A Systematic Review, Several countries, 2021).

\begin{tabular}{|c|c|c|c|c|c|}
\hline $\begin{array}{l}\text { Author, year, } \\
\text { country }\end{array}$ & $\begin{array}{c}\mathrm{n}^{\mathrm{a}},(\% \\
\text { of women), } \\
\text { age }\end{array}$ & Behavioural outcome & $\begin{array}{l}\text { Examined factors } \\
\quad \text { (in addition } \\
\text { to demographics }{ }^{\text {b) }}\end{array}$ & $\begin{array}{c}\text { Key results (significant } \\
\text { associations or significant group } \\
\text { differences) }\end{array}$ & $\begin{array}{l}\text { Quality } \\
\text { (NOS) }^{c}\end{array}$ \\
\hline
\end{tabular}

familiarity, mood, ethical concern, eating attitudes.

Forleo et al., 2017, $\quad n=548,(67.1), M=$ Adherence to new Italian Italy 25.05

Izmirli and Phillips $n=3,433$, (NR), NR Consumption of animal 2011, Multiple countries

Kawasaki et al., 2021, $\quad n=215,(100)$, Japan

$$
M=20
$$
Higher scores for healthful plantand appreciation for food" sub-

Pocol et al., 2020,

Romania, Bulgaria

$n=2,378$, (NR), NR Adherence to mixed or

and Moldova.

Menozzi et al 2017, $\quad n=231,(61.9), M=$
Italy

Olfert et al., 2020., United States

$n=1,078$,

$(66,6), \mathrm{NR}$

Argentina, Brazil,

France, United States

$n=1,695,(65.5), \quad$ Beef consumption

$M=22 \operatorname{SD} 2.53$ majority of the Weight-Loss participants followed their diet for 1-3 months. Strictness of diets did not differ. Main reasons cited for stopping the vegetarian diet were (Continued on following page)

Mediterranean food pyramid products

Healthful plant-based diet

Mindful eating

Attitudes towards animals, and perceived importance of world issues. home or away, BMl, proenvironmental behaviours, knowledge on daily caloric needs, physical activity (sports). five (26\% of the sample), the least compliant to Mediterranean Pyramid, showed an above average consumption of meat and processed meat products, younger students, a higher percentage of females and students living with parents.

Students avoiding some meats cited the environment as the most important reason, and then health, whereas most vegetarian students gave their health as the main reason. Vegans had greater concern for animal welfare. based diet were correlated with higher "health of the planet" and "awareness scores. "Non-judgmental awareness" was correlated with a low intake of healthful plant-based foods.

EAT-lancet diet adherence was very

Anthropometric measurements, dietary intake, dietary cost and eating out of home

Residence, weight. vegetarian diets.

Adherence to vegetarian

diet

Perceptions of campus environment, waist, and hip circumference, fruit and vegetable intake, fat intake, stress, eating attitudes, physical activity, sleep quality.

Attitudes toward beef, and toward vegetarians.

Beef consumption

low. No associations found.

Mixed diet was slightly higher among men. Semi-vegetarian, ovo-lactovegetarian, and lacto-vegetarian diets, was slightly higher among women. Mixed diet decreases with age, while semivegetarian and ovo-lacto-vegetarian diets, increases slightly with age.

Attitudes, subjective norms, perceived Students enrolled in social sciencesbehavioural control (PBC), intention, topic of study.

related were less likely to taste the insect-based food product compared to students in food and environmental sciences-related. intention is the main predictor of the behaviour, followed by perceived behavioural control.

Vegetarians had higher stress,

consumed significantly more servings of fruits and/or vegetables per day and obtained a lower percentage of their daily caloric intake from fats than nonvegetarians. Vegetarians had similar mean $\mathrm{BMl}$ as nonvegetarians. Men consumed beef significantly more often than women. Consumption was significantly highest in Brazil, followed by Argentina, then the USA, and finally France. Men ate beef significantly more frequently than did women in Brazil, and the United States, but not in Argentina. Vegetarian group remained on their diet for more than 1 year, whereas the

Low

Moderate

Adherence to vegetarian, Reasons for discontinuing diets vs. weight loss diet
Smith et al., 2000
United States 
TABLE 1 | (Continued) Articles included in the review. (What Influences the Sustainable Food Consumption Behaviours of University Students? A Systematic Review, Several countries, 2021).

$\begin{array}{lcc}\begin{array}{l}\text { Author, year, } \\ \text { country }\end{array} & \begin{array}{c}\mathrm{n}^{\mathrm{a}},(\% \\ \text { of women), } \\ \text { age }\end{array} & \begin{array}{c}\text { Behavioural outcome } \\ \text { Egamined factors } \\ \text { (in addition }\end{array} \\ \text { to demographics }\end{array}$

$\begin{array}{cc}\begin{array}{c}\text { Key results (significant } \\ \text { associations or significant group } \\ \text { differences) }\end{array} & \begin{array}{c}\text { Quality } \\ \text { (NOS) }^{\mathrm{c}}\end{array} \\ \end{array}$

"missed eating (meat),"

"inconvenience," and "did not get adequate nutrients."

Spencer et al., 2007, United States

NR

Self-reported vegetarian diet

Prevalence vegetarian diet

$$
17-28
$$$$
\text { = }
$$

Vizcaino et al., 2020, $\quad n=99$, (70), Median United States

$=18$ Interquartile range 18-19

Al-Domi H, 2011, Jordan

$$
\begin{gathered}
n=600,(37), M= \\
21.5 \text { SD } 2.85
\end{gathered}
$$

Alattar et al., 2020, United States

Lorenz et al., 2017 , Germany

Adherence to a plantbased diet

$n=238,(48), \mathrm{NR}$

$n=495,(54), M=21$

Range 18-58
Lorenz et al., 2018, $\quad n=384$, (47), Germany

$$
M=24.3
$$

Mondejar-Jimenez et al., 2017, Spain, Italy $n=380,(58), M=$ 20.62 SD 2.62
Selected demographic and lifestyle characteristics.

Self-regulatory system, variety of motivations. waste)

Plate waste
Visually estimated food leftovers
Food waste diversion behaviours

Leftover behaviour (Food
Demographic and socioeconomic characteristics.

Food management skills, food waste attitudes/emotions, perception of cost, food waste knowledge, general sustainability beliefs, perception of personal impact.

Personal (Attitudes, PBC, subjective norms, Intention, Personal Norms), social (presence of others), and environmental/situational factors (palatability, portion size, and time pressure)

Beliefs (constructs: environment, selfinterest, and resources), general attitude (towards the behaviour) and behavioural intention

Positive behaviour towards food waste, and proportion food wasted
Concern about food waste, moral attitude, subjective norms, perceived behavioural control, marketing/sale addiction, intention

Eating habits and level of physica activity.

Knowledge, attitudes (level of concern).
Vegetarians were more likely to eat more fruits and vegetables, be women, be Hindu, Buddhist, or Seventh Day Adventist, be politically liberal, have a $\mathrm{BMI} \leq 25$

The vegetarian group consisted mainly of Moderate women, aged between 17 and 20 years, with low income, non-smokers, physically active, using vitamin and mineral supplements and having a normal BMI. Successful adherents had higher levels of Moderate value, self-efficacy, planning/stimulus control and positive affect, were seventeen times more likely to report "To manage or treat a medical condition" and were 94\% less likely to report 'To maintain and/or improve my health' as motivation. No differences between the food plate Low wasted between women and men, except for meat wasted, women waste slightly more than men. Food waste was low in general.

The composting index was negatively correlated with food waste diversion intent, but attitudes toward composting were still positively correlated.

Perceptions of food (portions size and palatability) was related to food leftovers. For participants under time pressure, gender (being female) becomes a significant determinant for leftover behaviour. Time pressure was not a direct environmental determinant of leftovers.

Larger perceived portion size related to increased leftovers, and more positive taste evaluation related to lower leftovers. Both situational variables are significantly correlated with the selfinterest but not with pro-environmental or resource efficiency beliefs.

Subjective norms and perceived behavioural control promote the positive behaviour. Marketing/sale strategies "addiction" decreased the positive behaviour. The strongest positive significant total effect on behaviour comes from subjective norms.

Food waste was slightly higher among Low women. Lunch generated more wasted food than dinners.

Food waste reduction behaviour was negatively associated with higher levels of concern about "the risk of eating unsafe food because is no longer fresh," belief that "only $10 \%$ of the food purchased gets thrown away" (compared to those who believe that higher percentages of (Continued on following page) 
TABLE 1 | (Continued) Articles included in the review. (What Influences the Sustainable Food Consumption Behaviours of University Students? A Systematic Review, Several countries, 2021).

\begin{tabular}{|c|c|c|c|c|c|}
\hline $\begin{array}{l}\text { Author, year, } \\
\text { country }\end{array}$ & $\begin{array}{c}\mathrm{n}^{\mathrm{a}},(\% \\
\text { of women), } \\
\text { age }\end{array}$ & Behavioural outcome & $\begin{array}{l}\text { Examined factors } \\
\quad \text { (in addition } \\
\text { to demographics }{ }^{b} \text { ) }\end{array}$ & $\begin{array}{c}\text { Key results (significant } \\
\text { associations or significant group } \\
\text { differences) }\end{array}$ & $\begin{array}{l}\text { Quality } \\
\text { (NOS) }^{c}\end{array}$ \\
\hline
\end{tabular}

food get thrown away," and believing that "packaging of the food thrown in the trash is a larger environmental problem than food waste."

Wu, et al., 2019, China $n=551,(46.1)$, NR Plate waste

Anh et al., 2019, Vietnam
$n=791,(\mathrm{NR}), \mathrm{NR}$

Sustainable consumption behaviour in food
Anh et al., 2020,

Vietnam

Campbell-Arvai, 2015, $\quad n=320$, (52.5), NR United States
Attitudes, perceived behavioural control, subjective norms, canteens characteristics (e.g., food not tasty, too much food provided), factors related to food waste avoidance (e.g., save money, felling of guilt)

Environmental awareness and action economical and effective options, and sustainable buying options.
Gender, religion, academic year, love relationship, residence status.

Demographic and socioeconomic characteristics, value orientation, proenvironmental worldview (NEP - New environmental paradigm scale), and food-related environmental beliefs

Knowledge, attitudes.

Pro-environmental behaviours (food related)
Israel

Kamenidou et al. 2019., Greece

$n=252,(54.8), \mathrm{NR}$

Sustainable food consumption behaviour
Social norms, ecological purchase behaviour, and clusters based on demographic characteristics.
Perceived moral intensity of climate change

Perceived barriers
Mäkiniemi and Vainio, $\quad n=350,(80), M=24 \quad$ Climate-friendly food 2014, Finland choices
A perception that avoiding food waste is difficult, and higher living expenses were factors promoting food waste. Subjective norms, attitudes, gender, and major had insignificant impacts. Male students wasted significantly less staple foods than female students.

The construct of "Environmental awareness and action" (I cook in an energy-efficient way, I avoid eating convenience food because of plastic waste, I use containers instead of plastic wraps/bags, I sort the inorganic or organic waste before throwing into the trash) had the strongest positive impact on the studied outcome.

Being in a relationship increased the Low probability of sustainable consumption behaviour. Higher BVO (Biospheric value orientation) and environmental belief scores were associated with higher environmental behaviour scores. NEP scores (New environmental paradigm), when controlling for BVO, environmental beliefs and gender, did not make a significant contribution to the model. Males had lower environmental behaviour scores than females. Women had more pro-environmental behaviour than men. Attitudes were the best predictor of proenvironmental food related behaviour. Lack of knowledge on environmental impact of food consumption was negatively correlated to outcome.

Two students' segments were identified Low based on Sustainable food consumption (SFC) behaviour, social norms and ethical behaviour: "The underconsideration students" and "The negatively positioned students". None of them has a high level of SFC, but the first and larger segment is more positively predisposed towards it.

Probable Seriousness of Consequences Low was by far the most important of the three moral intensity dimensions. Wanting to eat the same as before, Disbelief in climate effects of food choices and lack of time had the greatest negative effect on climate-friendly food choices. Being male decreases the likelihood of choosing climate-friendly foods.

Muslim consumers have lower scores Low on the evaluated factors, except for convenience factor correlation.
Moderate 
TABLE 1 | (Continued) Articles included in the review. (What Influences the Sustainable Food Consumption Behaviours of University Students? A Systematic Review, Several countries, 2021).

\begin{tabular}{lcc}
\hline $\begin{array}{c}\text { Author, year, } \\
\text { country }\end{array}$ & $\begin{array}{c}\mathrm{n}^{\mathrm{a}},(\% \\
\text { of women), } \\
\text { age }\end{array}$ & $\begin{array}{c}\text { Behavioural outcome } \\
\text { (in addition }\end{array}$ \\
& to demographics ${ }^{\mathrm{b}}$ )
\end{tabular}

promotion/diffusion, governmental efforts

$\begin{array}{cc}\begin{array}{c}\text { Key results (significant } \\ \text { associations or significant group } \\ \text { differences) }\end{array} & \begin{array}{c}\text { Quality } \\ \text { (NOS) }^{\mathrm{c}}\end{array}\end{array}$

\begin{tabular}{|c|c|c|c|}
\hline $\begin{array}{l}\text { Schoolman, 2019, } \\
\text { United States }\end{array}$ & $\begin{array}{l}n=2,328 \\
(52,9), N R\end{array}$ & Ethical food consumption & Emotional experience of shopping \\
\hline $\begin{array}{l}\text { Vecchio and } \\
\text { Annunziata, 2013, } \\
\text { Italy }\end{array}$ & $n=500,(58.6), \mathrm{NR}$ & $\begin{array}{l}\text { Sustainable food products } \\
\text { purchase behaviour }\end{array}$ & $\begin{array}{l}\text { Personality, attitudes, values, } \\
\text { lifestyles, demographic and socio- } \\
\text { economic characteristics. }\end{array}$ \\
\hline
\end{tabular}

Specific needs were the main contributing factor and the strongest predictor in discriminating between Muslim and non-Muslim consumers' green food consumption.

Purchasing "ethical" or "sustainable" Moderate foods is associated with experiencing shopping for food as enjoyable. Responsible food consumer cluster consisted of: urban citizens, live alone or with other students, medium-high household incomes, higher number of worker-students. Inattentive food consumer cluster consisted of: low degree of knowledge of the main sustainability issues, low-involvement attitude to virtuous lifestyle habits, do not think that their generation is adopting unsustainable consumption patterns, non-urban areas and families with medium household income. Potentially sustainable food consumer consisted of: least satisfied with the available information on sustainable food, majority of students that live in non-urban areas and are part of families with a medium household income.

\footnotetext{
${ }^{a} n$, sample size.

${ }^{b}$ Examined factors, in addition to demographics such as sex, age.

${ }^{c}$ NOS, New-Castle Ottawa Scale.

${ }^{d}$ Multiple countries: China, Czech Republic, United Kingdom, Iran, Ireland, South Korea, Macedonia, Norway, Serbia, Spain, and Sweden.

$N R$, no reported; $M$, mean, $S D$, standard deviation.
}

behaviours of university students. The results are divided into proposed operational categories of Sustainable Food Consumption (SFC) behaviours. Figure 2 presents the proposed categories and summarizes the corresponding target behaviours extracted from articles. An exhaustive list of behavioural outcomes was extracted from the selected articles, and data reduction of similar behaviours was performed until reaching saturation.

The articles analysed related to a broad range of sustainable food consumption behaviours of university students, from "farm to dump," reflecting food consumption choices based on a) how food is produced (e.g., organic), b) the environmental impact of food transport or "food miles" (e.g., consumption of local products), c) food packaging, d) specific foods choices or dietary patterns (e.g., plan-based diets, moderate meat consumption), and e) food waste. Most studies in our sample focused on dietary behaviours, followed by food waste. The frequencies of publications per category are presented in the PRISMA flowchart (See Figure 1). Outcomes related to air-transported foods avoidance, consumption of seasonal products, or those with low environmental impact (e.g., efficient water, land use, sustainable fisheries) were covered by articles that examined SFC behaviour as an umbrella concept. No studies about cultured meat were eligible for inclusion.
A higher proportion of students already consume organic food, with reports of frequent consumption ranging from $44 \%$ [57] to $89 \%$, [58]; seasonal and local food products, reported as the top SFC behaviours by Kamenidou et al. [51] with mean scores of 5.46 and 5.10 out of 7 , respectively; avoid some meats (47.4\%) [26] or avoided plastic bottled water (34\%) [47]. This contrasts with the relatively lower prevalence of self-declared "flexitarians" (15.4\%) [33], “pescovegetarians" (11.6\%) [33], "semi-vegetarians," 6\% [29] to $12.1 \%$ [33], vegetarians, ranging from $3.9 \%$ [26] to $25 \%$ [59], and vegans, ranging from $0.4 \%$ [26] to $1.8 \%[59]$.

\section{From the Farm: Sustainable Production}

Six studies were focused on consumption of organic food (OF) $[32,34,40,57,58,60]$. Three articles reported that knowledge and attitudes about $\mathrm{OF}$ had a positive relationship with the purchase and consumption of these foods (Correlation coefficients ( $r$ ) between 0.24 and 0.28) [32, 34, 58]. Perceived safety, nutritional value and the perception that organic is fresher and has better taste, were also factors correlated with organic food consumption [58]. Positive associations were also found between the knowledge score of students and organic food consumption. McReynolds et al. [34] found that students with 


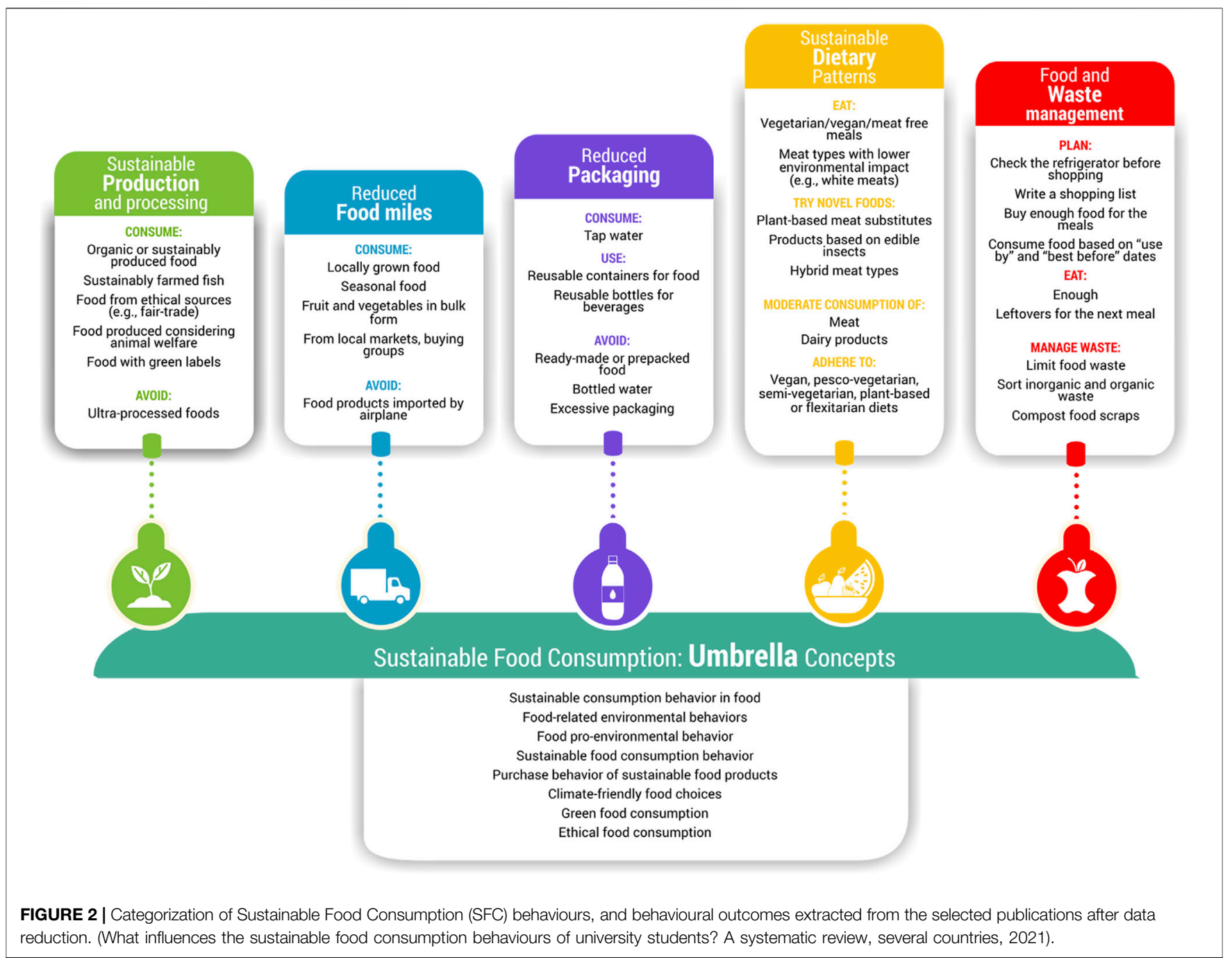

experience growing food had a higher frequency of OF purchase consumption $\left(\mathrm{Chi}^{2} p=0.01\right)$ and organic fruit consumption $\left(\mathrm{Chi}^{2} p=0.02\right)$ compared to students without such experience. Females had greater intention to buy organic food but there were no differences in consumption compared to males [34]. A perceived health risk reduction of $\mathrm{OF}$ consumption was associated with incremented frequency of $\mathrm{OF}$ consumption [40] and Green Perceived Value (GPV) constructs, especially emotional value, had a significant positive effect on purchase intentions, which in turn, had a positive effect on purchase behaviour moderated by food neophobia. In contrast, reported barriers to buying OF were higher price (35.9\%), OF perceived as not attractive (20.5\%), and distrust in OF being "better" or "nonchemical" (19.8\%) [61].

\section{Reduced Food Miles}

One study examined the association of local identity, brand valuation and the moderating effect of perceived availability on purchasing four local brands of tomato sauce, rice, mineral water, and a traditional local cake. A direct effect of local identity on effective purchase was only found for the local brand of mineral water, while there was a positive indirect effect of local identity through brand valuation for tomato sauce, rice, and cake brands. This indirect effect was further conditioned to the perceived availability of the tomato sauce and rice brands [45].

\section{Reduced Food Packaging}

One article compared the frequency of tap water consumption with the frequency of bottled water consumption. Compared to university faculty and staff, students were the most frequent consumers of bottled water (43.9 and 39.3\%, respectively). Agreement (one total disagree to five total agree) with the statement "it is safer to drink bottled water than tap water" varied among bottled water consumers (Kruskal-wallis $p=0.00$ ), multiple comparison showed that differences arose from consumers of $\geq 6$ bottles per week having a median of 3 range one to four compared to those consuming one to five bottles per week (Median 2 range 1-2) [47].

\section{The Fork: Sustainable Dietary Patterns}

Fourteen articles assessed food-based behaviours. Eleven examined the adherence to full dietary patterns and three 
addressed more narrowly the consumption or substitution of meat and animal products.

Studies that examined factors associated with adherence to vegetarian diets $[35,38,39,59,62,63]$ found that a vegetarian diet pattern was associated with being female, non-smoker, lower proportion of daily caloric intake from fats, a lower-income, and use of vitamin-mineral supplements. Body mass index (BMI) and physical activity yielded mixed results $[35,38,59]$. Spencer et al. [38], found vegetarians had BMI $\leq 25$ [38], Suleiman and colleagues [59] found that vegetarianism was associated with a normal BMI and being physically active among students in Jordan [59], while Olfert et al. [35], did not find significant differences in BMI and physical activity levels between vegetarian and non-vegetarian students in the USA. Surprisingly, Barros et al., in a model adjusted by sex, age, BMI, cohabitants and major, found that students who reported prejudicial alcohol had an $2.6 \%(95 \%$ CI 1.4;4.7) increased odds of adopting vegetarian diet [62], and Olfert et al [35] found higher stress levels among vegetarians.

Forestell and colleagues [64] examined food restraint, demographic, personality and lifestyle characteristics among vegetarian, pesco-vegetarian, semi-vegetarian and flexitarian compared to omnivores. Vegetarians and pesco-vegetarians were more open to new experiences, variety seeking, and had less food neophobia. Vegetarians and pesco-vegetarians did not differ from omnivores in their restraint level, while semivegetarians and flexitarians were more restrained than omnivores.

Two studies addressing plant-based diets took a more specific approach to understand factors for successful adherence in the USA, and the role of mindful eating on the adherence to healthful vs. unhealthful plant-based diets in Japan [36, 65]. Successful adherents to a plant-based diet, compared to those who tried without success, had higher levels of value, self-efficacy, planning/ stimulus control and positive affect, while self-monitoring and self-criticism were negatively correlated. They were also seventeen times more likely to report "To manage or treat a medical condition," almost seven times more likely to report "To align with my ethical beliefs," and 94\% less likely to report "To maintain and/or improve my health."

Students who had higher scores for healthful plant-based diet (hPDI-J) also had higher total "health of the planet" and "awareness and appreciation for food" mindful eating subscores. Instead, "non-judgmental awareness" was correlated with a low intake of healthful plant-based foods. Smith et al [39] compared groups of students who had followed vegetarian and/or weight-loss diets and found that the vegetarian group could adhere to their diet for longer. The top reasons to drop the vegetarian diet were missing meat and concerns about nutrient intake [39]. A study in Albania found very low adherence to the EAT-Lancet reference diet and did not find any associations with the factors of interest (BMI, cost and eating out of home) [66]. Lower adherence to the Mediterranean Food Pyramid reference diet and higher meat consumption was found in a cluster of younger students, more females and living with parents [44].
Three articles examined factors concretely related to meat consumption, such as meat avoidance [26], beef consumption [27], and consumption of an insect-based product [41]. A study conducted in 11 countries across Europe and Asia found significant differences regarding the reasons to avoid meat among different groups of meat avoiders. The environment was the main reason for those who avoid some meats; health was the most important reason for most vegetarians, whereas vegans were most concerned about animal welfare-related reasons [26]. Beef consumption frequency was significantly correlated with being male in the USA, France, Brazil, but not in Argentina [27]. Intention and Perceived Behavioural Control (PBC) were the main predictors of tasting an insect-based food product. Students enrolled in social sciences were less likely to taste cricket flour than those in food and environmental sciences [41].

\section{To the Dump: Food and Waste Management}

Two main behavioural outcomes were studied. Two studies measured self-reported food waste reduction behaviours (e.g., making a shopping list, using leftovers) [30, 42], while five observed the amount of food waste (plate waste/leftovers) [46, $55,56,67,68]$, and one assessed both [28].

Three out of the eight articles dealing with food waste reported significant associations with gender. One study in Spain found a significant association between higher food waste and being female [46], while two other studies found that females wasted slightly more meat [67] and staple [56]. Higher-income/living expenses were associated with higher food waste in two studies $[42,56]$. Composting [30], "addiction to sales," [28] concerns about food safety, and lack of knowledge about food waste (the belief that only $10 \%$ of the food purchased gets thrown away, not knowing that waste is a more serious problem than packaging) [42] were negatively associated with food waste reduction behaviours.

Three papers that examined TPB constructs had mixed results. Alattar and colleagues found that attitudes and intent were the strongest predictors of food waste diversion behaviours among university students in the USA [30]. In contrast, Mondejar-Jimenez et al. [28] found among their student sample in Italy and Spain that the strongest predictor of (correct) behaviour towards food waste were subjective norms followed by PBC. Wu et al. [56] found that more food was wasted in association with low PBC in China, while subjective norms and attitudes had no significant association.

Lorenz et al. [55] explored personal, social and environmental (situational) determinants associated with leftover behaviour, revealing interactions between personal and environmental factors. While time pressure was not a direct environmental determinant of leftovers, being female becomes a significant determinant for this behaviour among students under time pressure. There was a significant relationship between perceptions of food (portions size and palatability) and food leftovers. No significant association was found between the presence of others and food leftovers. In a later study, the 
same authors, also in Germany [68], broke down attitudes into more specific subsets of beliefs (self-interest, pro-environmental, resource efficiency), finding interactions between situational variables and self-interested beliefs.

\section{Umbrella Concepts}

Ten of the included articles addressed SFC, integrating different behaviours measured by an index, composite measure or score (See Supplementary Material). Students "in a relationship" had higher SFC levels than "single" (Mean Difference $=-0.16, p<0.05$ ) [49]. High levels of "environmental awareness and action" (engaging in other behaviours such as energy-efficient cooking, avoid plastic waste, and sorting inorganic and organic food) $(\beta=0.46, p<0.05)$ [49], intention $(\beta=0.74, p<0.001)$, perceived seriousness of consequences of climate change $(\beta=0.10, p<0.05)$ [52], biospheric value orientation (BVO) $(\beta=0.28, p<0.001)$, and environmental beliefs $(\beta=0.24, p<0.001)$ [31] were associated with SFC behaviours. Attitudes $(\beta=0.28, p<0.001)$ and knowledge on the environmental impact of food consumption $(\beta=0.14, p<0.01)$ also were associated with SFC [50]. Being male was associated with lower SFC behaviour in two samples of students in the United States $(\beta=-0.11, p<0.05)[31]$ and Finland $(\beta=-0.13$, $p<0.01$ ) [52]. There were no significant differences in green food consumption between Muslim and non-Muslim students in Malaysia, despite significant differences in personal needs, environmental values and perceptions about government efforts related to green food [54]. No other demographic characteristics were significant predictors of SFC.

Two groups of researchers took a factor analysis approach to identify student segments. Kamenidou et al. [51] identified two segments based on SFC behaviour, social norms, and ethical behaviour: "The under-consideration students" and "The negatively positioned students". None of the segments show higher SFC levels, but the first and larger segments were positively predisposed towards it. Frequent SFC behaviours were limited to seasonal and local food consumption. Vecchio and Annunziata [43] identified three clusters: "responsible food consumer" (urban citizens, live alone or with other students, medium-high household incomes, higher amount of worker-students), "inattentive food consumer" (low degree of knowledge of sustainability issues, low-involvement attitude to virtuous lifestyle habits, and medium household income), and "potentially sustainable food consumer" (least satisfied with the available information on sustainable food, majority of students that live in non-urban areas, medium household income). Under the label of "ethical food consumption," Schoolman [37] measured purchase frequency of products that can fall into SFC (locally grown/processed food, organic food, fair trade food, food from humanely treated animals, and fish from sustainable fisheries). This study found that, for each additional point on the ethical food consumption index, students were $51.1 \%$ more likely, to declare they enjoyed shopping food daily.

\section{Quality Assessment}

Scores for the included papers ranged from 3 to 8 , out of 10 possible points, with a median of 5 points; $75 \%$ of the articles were classified as low quality and $25 \%$ rated moderate. Out of the 17 studies that implemented regression methods, seven adjusted or stratified by sex or age. Thirty-nine studies did not report the response rates, and 26 did not justify the sample size. The quality assessment scores of selected studies are listed in the supplementary material.

\section{DISCUSSION}

Based on data from 40 included publications, we found that literature evaluating the related factors associated with SFC behaviours has focused mainly on personal factors, such as intention, knowledge, attitudes, lifestyle, values and beliefs, and there is scarce evidence on social and environmental (situational) factors.

A higher proportion of students already consume organic, seasonal and local food, fewer avoid some meats, and there is a relatively low prevalence of self-declared "flexitarians," "pescovegetarians," "semi-vegetarians," vegetarians, and vegans. This shows a higher reported adoption of SFC behaviours with lower planetary health potential: while the sustainability of organic food can be limited [69] and organic production is only one of many forms of sustainable agriculture, the livestock sector contributes to an estimated $14.5 \%$ of the total human-induced GHG emissions [70].

\section{Underlying Factors and Characteristics of Sustainable Food Consumers}

Except for food waste $[46,56]$, being a woman was reported as a factor related to SFC [31, 59], but situational factors moderated this association (e.g., time pressure) [55]. Factors such as knowledge and attitudes yielded mixed results. Concern about food safety was positively associated with organic food consumption [58] but negatively associated with food waste prevention [42]. Composting was associated with higher food waste [30].

Concerning lifestyles, sustainable consumers tended to have healthier lifestyles, better dietary habits [35, 38, 59], and enjoy food shopping more [37] than less sustainable consumers. Similarly, students were able to adhere to vegetarian diets for longer than to weight-loss diets [39]. However, weight control and food restraint associated with SFC require further analyses as they can incur health risks, and the healthfulness and sustainability of eating behaviours are often dose-dependent. Two studies found that vegetarians had higher levels of stress [35] and prejudicial alcohol consumption [62], in samples of university students in the United States, and Brazil. These adverse associations deserve further examination. Similar attention is needed about the consumption of plant-based meat substitutes, included as outcome in one of the selected studies [51] as they have the benefits of vegetable consumption but can be highly processed.

Significant associations were found between knowledge and outcomes for organic food consumption [34] and making a shopping list (food waste prevention) [42]. Conversely, the lack of knowledge on the environmental impact of food was associated with less sustainable food consumption [50]. In 
particular, participants underestimated the environmental impact of meat consumption [50] and food waste [42], and overestimated the impact of other behaviours such as food packaging [42]. This low awareness about the environmental impact of food choices is aligned with previous findings [71]. Other studies did not find significant associations between knowledge and organic food consumption [32, 58], suggesting the need for further examination to disentangle the mechanisms involved in knowledge as a predictor of behaviour.

Behavioural outcomes, such as meat reduction and avoidance, were associated with different factors depending on the reported motivations for eating behaviour (health, environment, animal rights). This is compatible with literature on factors linked to different eating motives [72, 73].

\section{Operational Categorization of Sustainable Food Consumption Behaviours}

There is still a lack of operational, standardized behavioural definitions of sustainable food consumption from the consumer perspective [12, 74]. Dietary behaviours, such as adherence to vegetarian or flexitarian diets, followed by food waste, were the most studied behavioural categories. While the categories are not meant to be exhaustive, they cover a diverse variety of behaviours.

The lack of behavioural measures was a common reason for exclusion of otherwise eligible studies. Measuring behaviour can be challenging when studying food intake, especially when these behaviours are uncommon (e.g., cultured-meat, edible insects, meat-mushroom blends). Menozzi et al. [41] on cricket flour presents a sound methodological solution to overcome this problem. Behavioural data collected in virtual reality is also a promising alternative as data can be comparable to real-life consumption data [75].

\section{Strengths and Limitations}

To the author's knowledge, this is the first literature review integrating a broad range of sustainable food consumption behaviours for a specific population. This comes with the challenge of synthesizing a diversity of outcomes measured in different ways, as studies included were highly heterogeneous, which was a barrier for meta-analysis. However, examining SFC as an umbrella concept, allowed identifying possibly conflicting interactions between different behaviours and factors that would not be possible when reviewing articles for a single target behaviour. We followed a strict definition of behavioural outcomes, excluding studies that did not include self-reported or observed behavioural measures. This was essential to answer the main research question but excluded many otherwise eligible studies that measured acceptance, willingness, attitudes, or behavioural intention, possibly affecting the geographic coverage and variety of target behaviours captured by the review.

The selected studies covered three continents and 30 countries in all income economies levels. Relevant studies that exceeded the scope of this review, e.g. qualitative, case studies, focused on awareness, etc., have been conducted in other countries [18, 76-85]. Since most of the selected studies rely on convenience sampling, generalizations about the country population are not possible. Yet, relative homogeneity of the population supports conclusions about young adults and university students with caution.

The examination of social and situational factors is rather neglected in the selected studies at hand. This may be due to higher interest in personal factors, the fact that some social or environmental/situational factors are classified as personal, but it may also be due to the observational nature of the study designs covered in this review. Other reviews conducted on experimental study designs on meat consumption, for example, yielded more balanced proportions of personal and environmental/situational determinants [86-88].

\section{Conclusion}

Our findings support previous evidence about the health and environmental co-benefits of sustainable food consumption [7-10], from the consumer behaviour perspective. Healthy lifestyles of sustainable food consumers suggest possible synergies between environmental and health motivations of food choice and longer-term adherence to healthy diets. Future research areas can examine the effects of communication framings that emphasize the individual health or pro-social environmental benefits of SFC in different populations. There is also a need to further examine the behavioural aspects related to the co-benefits and also the management of risks associated to SFC, at the lifestyle and health outcomes level. Social norms [89, 90], including related variables as eating with others, and situational factors such as time pressure, portion size, palatability [55], availability of sustainable alternatives, food repositioning or labelling [86] deserve further examination. The moderation effects of social and environmental factors on personal factors related to sustainable food consumption reveal opportunities to design choice architecture interventions. Future research could evaluate the interaction between possibly conflicting predictors of different SFC behaviours, the disentangling mechanisms behind attitudes and knowledge as a predictor of behaviour, and the factors to adopt SFC in male consumers.

Practical implications include: for universities, the need for monitoring the effects of their food environments, and situational factors, on the food choices of students; for key actors in the production side of the food chain, the almost absent sustainable produced food consumption alternatives, beyond organic food, show the need for more transparency about other aspects of production sustainability that are increasingly relevant for young consumers; and for food policy actors this work adds to the growing body evidence about diverse SFC behaviours that can be promoted to advance health and sustainability targets. The proposed categorization of behaviours is not meant to be exhaustive but contributes to the behavioural operationalization of sustainable food consumption including but not limited to sustainable diets.

From a planetary health perspective, the sustainability of food consumption becomes a pressing public health issue, as it is recognized that adverse effects on population health result from unsustainable and unhealthy food consumption. This urgency is consistent with an evolving view of sustainable development that acknowledges that healthy economies and societies depend on the life-sustaining capabilities of the ecological system [91]. 


\section{AUTHOR CONTRIBUTIONS}

LAS and ZR-D designed the research and led the review team; BM and DK-H developed and updated the search strategies; LAS, ZR$\mathrm{D}, \mathrm{MB}, \mathrm{AM}, \mathrm{MG}, \mathrm{BM}-\mathrm{U}, \mathrm{GG}$, and AR conducted screening and data extraction; LAS and ZR-D analysed the data and wrote the manuscript. LSS, OF, LAS, ZR-D, MB, AM, MG, BM-U, GG, and AR were involved in interpreting the results and editing the manuscript. LSS and OF supervised the research. All authors read and approved the final manuscript.

\section{FUNDING}

This project has received funding from the European Union's Horizon 2020 research and innovation programme under the Marie Skłodowska-Curie grant agreement No 801076, through

\section{REFERENCES}

1. Afshin, A, Sur, PJ, Fay, KA, Cornaby, L, Ferrara, G, Salama, JS, et al. Health Effects of Dietary Risks in 195 Countries, 1990-2017: a Systematic Analysis for the Global Burden of Disease Study 2017. Lancet (2019) 393(10184):1958-72. doi:10.1016/S0140-6736(19)30041-8

2. Vermeulen, SJ, Campbell, BM, and Ingram, JSI. Climate Change and Food Systems. Annu Rev Environ Resour (2012) 37(1):195-222. doi:10.1146/ annurev-environ-020411-130608

3. Willett, W, Rockström, J, Loken, B, Springmann, M, Lang, T, Vermeulen, S, et al. Food in the Anthropocene: the EAT-Lancet Commission on Healthy Diets from Sustainable Food Systems. The Lancet (2019) 393(10170):447-92. doi:10.1016/S0140-6736(18)31788-4

4. Whitmee, S, Haines, A, Beyrer, C, Boltz, F, Capon, AG, de Souza Dias, BF, et al. Safeguarding Human Health in the Anthropocene Epoch: Report of the Rockefeller Foundation-Lancet Commission on Planetary Health. The Lancet (2015) 386(10007):1973-2028. doi:10.1016/S0140-6736(15)60901-1

5. Food and Agriculture Organization of the United Nations (FAO). Definition of Sustainable Diets. In: International Scientific Symposium Biodiversity and Sustainable Diets: United against Hunger Rome. Rome, Italy: FAO (2010). p. 27.

6. Norwegian Ministry of the Environment. Oslo Roundtable on Sustainable Production and Consumption. Oslo, Norway: Norwegian Ministry of the Environment (1994).

7. Liu, Q, and Gao, J. Public Health Co-benefits of Reducing Greenhouse Gas Emissions. In: WK Al-Delaimy, V Ramanathan, and M Sánchez Sorondo, editors. Health of People, Health of Planet and Our Responsibility: Climate Change, Air Pollution and Health. Cham: Springer International Publishing (2020). p. 295-307. doi:10.1007/978-3-030-31125-4_23

8. Macdiarmid, JI, Kyle, J, Horgan, GW, Loe, J, Fyfe, C, Johnstone, A, et al. Sustainable Diets for the Future: Can We Contribute to Reducing Greenhouse Gas Emissions by Eating a Healthy Diet? Am J Clin Nutr (2012) 96(3):632-9. doi:10.3945/ajcn.112.038729

9. Skouteris, H, Cox, R, Huang, T, Rutherford, L, Edwards, S, and CutterMackenzie, A. Promoting Obesity Prevention Together with Environmental Sustainability. Health Promot Int (2014) 29(3):454-62. doi:10.1093/heapro/ dat007

10. Clark, MA, Springmann, M, Hill, J, and Tilman, D. Multiple Health and Environmental Impacts of Foods. Proc Natl Acad Sci USA (2019) 116(46): 23357-62. doi:10.1073/pnas.1906908116

11. Independent Group of Scientists appointed by the Secretary-General. Global Sustainable Development Report 2019: The Future Is Now - Science for Achieving Sustainable Development. New York: United Nations (2019). p. 216.

12. Rose, D, Heller, MC, and Roberto, CA. Position of the Society for Nutrition Education and Behavior: The Importance of Including Environmental the SSPH+ Global PhD Fellowship Programme in Public Health Sciences (GlobalP3HS) of the Swiss School of Public Health.

\section{CONFLICT OF INTEREST}

The authors declare that the research was conducted in the absence of any commercial or financial relationships that could be construed as a potential conflict of interest.

\section{SUPPLEMENTARY MATERIAL}

The Supplementary Material for this article can be found online at: https://www.ssph-journal.org/articles/10.3389/ijph.2021.1604149/ full\#supplementary-material

Sustainability in Dietary Guidance. J Nutr Edu Behav (2019) 51(1):3-15.e1 doi:10.1016/j.jneb.2018.07.006

13. Smetana, SM, Bornkessel, S, and Heinz, V. A Path from Sustainable Nutrition to Nutritional Sustainability of Complex Food Systems. Front Nutr (2019) 6:39. doi:10.3389/fnut.2019.00039

14. Béné, C, Fanzo, J, Prager, SD, Achicanoy, HA, Mapes, BR, Alvarez Toro, P, et al. Global Drivers of Food System (Un)sustainability: A Multi-Country Correlation Analysis. PLOS ONE (2020) 15(4):e0231071. doi:10.1371/ journal.pone.0231071

15. Fernández-Manzanal, R, Rodríguez-Barreiro, L, and Carrasquer, J. Evaluation of Environmental Attitudes: Analysis and Results of a Scale Applied to university Students. Sci Ed (2007) 91(6):988-1009. doi:10.1002/sce.20218

16. Ashraf, R, and Merunka, D. The Use and Misuse of Student Samples: An Empirical Investigation of European Marketing Research. J Consumer Behav (2017) 16(4):295-308. doi:10.1002/cb.1590

17. Bernardo, GL, Jomori, MM, Fernandes, AC, and Proença, RPd. C. Food Intake of university Students. Rev Nutr (2017) 30(6):847-65. doi:10.1590/167898652017000600016

18. Vermeir, I, and Verbeke, W. Sustainable Food Consumption Among Young Adults in Belgium: Theory of Planned Behaviour and the Role of Confidence and Values. Ecol Econ (2008) 64(3):542-53. doi:10.1016/j.ecolecon.2007.03.007

19. Bumbac, R, Bobe, M, Procopie, R, Pamfilie, R, Giușcă, S, and Enache, C. How Zoomers' Eating Habits Should Be Considered in Shaping the Food System for 2030-A Case Study on the Young Generation from Romania. Sustainability (2020) 12(18):7390. doi:10.3390/su12187390

20. Perignon, M, Vieux, F, Soler, L-G, Masset, G, and Darmon, N. Improving Diet Sustainability through Evolution of Food Choices: Review of Epidemiological Studies on the Environmental Impact of Diets. Nutr Rev (2017) 75(1):2-17. doi:10.1093/nutrit/nuw043

21. Muka, T, Glisic, M, Milic, J, Verhoog, S, Bohlius, J, Bramer, W, et al. A 24-step Guide on How to Design, Conduct, and Successfully Publish a Systematic Review and Meta-Analysis in Medical Research. Eur J Epidemiol (2020) 35(1) 49-60. doi:10.1007/s10654-019-00576-5

22. Page, MJ, McKenzie, JE, Bossuyt, PM, Boutron, I, Hoffmann, TC, Mulrow, CD, et al. The PRISMA 2020 Statement: an Updated Guideline for Reporting Systematic Reviews. BMJ (2021) 372:n71. doi:10.1136/bmj.n71

23. Garnett, T, Appleby, MC, Balmford, A, Bateman, IJ, Benton, TG, Bloomer, P, et al. What Is a Sustainable Healthy Diet? A Discussion Paper. Oxford: Food Climate Research Network (FCRN) (2014). p. 31.

24. Gonzalez Fischer, C, and Garnett, T. Plates, Pyramids, Planet: Developments in National Healthy and Sustainable Dietary Guidelines: A State of Play Assessment. Oxford: Food and Agriculture Organization of the United Nations and The Food Climate Research Network at The University of Oxford (2016). p. 70.

25. Wells, GA, Shea, B, O'Connell, D, Peterson, J, Welch, V, Losos, M, et al. The Newcastle-Ottawa Scale (NOS) for Assessing the Quality of Nonrandomised 
Studies in Meta-Analyses (2021). Available from: http://www.ohri.ca/ programs/clinical_epidemiology/oxford.asp (Accessed Mar 24, 2021).

26. Izmirli, S, and Phillips, CJC. The Relationship between Student Consumption of Animal Products and Attitudes to Animals in Europe and Asia. Br Food J (2011) 113(2-3):436-50. doi:10.1108/00070701111116482

27. Ruby, MB, Alvarenga, MS, Rozin, P, Kirby, TA, Richer, E, and Rutsztein, G. Attitudes toward Beef and Vegetarians in Argentina, Brazil, France, and the USA. Appetite (2016) 96:546-54. doi:10.1016/j.appet.2015.10.018

28. Mondéjar-Jiménez, J-A, Ferrari, G, Secondi, L, and Principato, L. From the Table to Waste: An Exploratory Study on Behaviour towards Food Waste of Spanish and Italian Youths. J Clean Prod (2016) 138:8-18. doi:10.1016/ j.jclepro.2016.06.018

29. Pocol, CB, Marinescu, V, Amuza, A, Cadar, R-L, and Rodideal, AA. Sustainable vs. Unsustainable Food Consumption Behaviour: A Study Among Students from Romania, Bulgaria and Moldova. Sustainability (2020) 12(11):4699. doi:10.3390/su12114699

30. Alattar, M, DeLaney, J, Morse, J, and Nielsen-Pincus, M. Food Waste Knowledge, Attitudes, and Behavioral Intentions Among university Students. J Agric Food Syst Community Dev (2020) 9(3):1-16. doi:10.5304/ jafscd.2020.093.004

31. Campbell-Arvai, V. Food-related Environmental Beliefs and Behaviours Among university Undergraduates. Int J Sustain High Educ (2015) 16(3): 279-95. doi:10.1108/ijshe-06-2013-0071

32. Dahm, MJ, Samonte, AV, and Shows, AR. Organic Foods: Do Eco-Friendly Attitudes Predict Eco-Friendly Behaviors? J Am Coll Health (2009) 58(3): 195-202. doi:10.1080/07448480903295292

33. Forestell, CA, Spaeth, AM, and Kane, SA. To Eat or Not to Eat Red Meat. A Closer Look at the Relationship between Restrained Eating and Vegetarianism in College Females. Appetite (2012) 58(1):319-25. doi:10.1016/ j.appet.2011.10.015

34. McReynolds, K, Gillan, W, and Naquin, M. An Examination of College Students' Knowledge, Perceptions, and Behaviors Regarding Organic Foods. Am J Health Edu (2018) 49(1):48-55. doi:10.1080/19325037.2017.1399837

35. Olfert, MD, Barr, ML, Mathews, AE, Horacek, TM, Riggsbee, K, Zhou, W, et al. Life of a Vegetarian College Student: Health, Lifestyle, and Environmental Perceptions. J Am Coll Health (2020) 1-8. doi:10.1080/07448481.2020.1740231

36. Vizcaino, M, Ruehlman, LS, Karoly, P, Shilling, K, Berardy, A, Lines, S, et al. A Goal-Systems Perspective on Plant-Based Eating: Keys to Successful Adherence in university Students. Public Health Nutr (2021) 24(1):75-83. doi:10.1017/S1368980020000695

37. Schoolman, ED. Doing Right and Feeling Good: Ethical Food and the Shopping Experience. Sociological Perspect (2019) 62(5):668-90. doi:10.1177/0731121419855980

38. Spencer, EH, Elon, LK, and Frank, E. Personal and Professional Correlates of US Medical Students' Vegetarianism. J Am Diet Assoc (2007) 107(1):72-8. doi:10.1016/j.jada.2006.10.034

39. Smith, CF, Burke, LE, and Wing, RR. Vegetarian and Weight-Loss Diets Among Young Adults. Obes Res (2000) 8(2):123-9. doi:10.1038/oby.2000.13

40. Giampietri, E, Bugin, G, and Trestini, S. Exploring the Interplay of Risk Attitude and Organic Food Consumption. Int J Food Syst Dyn (2020) 11(3): 189-201. doi:10.18461/ijfsd.v1li3.49

41. Menozzi, D, Sogari, G, Veneziani, M, Simoni, E, and Mora, C. Eating Novel Foods: An Application of the Theory of Planned Behaviour to Predict the Consumption of an Insect-Based Product. Food Qual Preference (2017) 59: 27-34. doi:10.1016/j.foodqual.2017.02.001

42. Principato, L, Secondi, L, and Pratesi, CA. Reducing Food Waste: an Investigation on the Behaviour of Italian Youths. Br Food J (2015) 117(2): 731-48. doi:10.1108/bfj-10-2013-0314

43. Vecchio, R, and Annunziata, A. Consumers' Attitudes towards Sustainable Food: a Cluster Analysis of Italian university Students. New Medit (2013) 12(2):47-55.

44. Forleo, M, Tamburro, M, Mastronardi, L, Giaccio, V, and Ripabelli, G. Food Consumption and Eating Habits: A Segmentation of university Students from central-south Italy. New Medit (2017) 16:56-65.

45. Fernández-Ferrín, P, Bande, B, Calvo-Turrientes, A, and Galán-Ladero, MM. The Choice of Local Food Products by Young Consumers: The Importance of Public and Private Attributes. Agribusiness (2017) 33(1):70-84. doi:10.1002/ agr.21470
46. Esteve Mas, MJ, Morata Verdugo, MP, González Santana, R, Blesa, J, and Frigola Canoves, A. Study of the Habits and Food Waste Production of Young university Students. Nutr Hosp (2020) 37(2):349-58. doi:10.20960/nh.02833

47. Díez, J, Antigüedad, I, Agirre, E, and Rico, A. Perceptions and Consumption of Bottled Water at the University of the Basque Country: Showcasing Tap Water as the Real Alternative towards a Water-Sustainable University. Sustainability (2018) 10(10):3431. doi:10.3390/su10103431

48. Anh, PT, Van Son, D, Hong, NTT, Huy, DTN, and Linh, NNK. Factors Affecting Sustainable Consumption Choice in the Field of Food and Drink: The Case of university Students in Hanoi. Int J Entrep (2019) 23(1S):1099.

49. Anh, PT, Lan, NTN, Hanh, NTM, Huy, DTN, and Loan, BTT. Sustainable Consumption Behaviors of Young People in the Field of Food and Drinks: A Case Study. J Secur Sustain Issues (2020) 9(May):36-47. doi:10.9770/ JSSI.2020.9.M(310.9770/jssi.2020.9.m(3)

50. Dopelt, K, Radon, P, and Davidovitch, N. Environmental Effects of the Livestock Industry: The Relationship between Knowledge, Attitudes, and Behavior Among Students in Israel. Int J Environ Res Public Health (2019) 16(8):1359. doi:10.3390/ijerph16081359

51. Kamenidou, IC, Mamalis, SA, Pavlidis, S, and Bara, a. E-ZG. Segmenting the Generation Z Cohort University Students Based on Sustainable Food Consumption Behavior: A Preliminary Study. Sustainability (2019) 11(3): 837. doi:10.3390/su1 1030837

52. Mäkiniemi, J-P, and Vainio, A. Moral Intensity and Climate-Friendly Food Choices. Appetite (2013) 66:54-61. doi:10.1016/j.appet.2013.01.026

53. Mäkiniemi, J-P, and Vainio, A. Barriers to Climate-Friendly Food Choices Among Young Adults in Finland. Appetite (2014) 74:12-9. doi:10.1016/ j.appet.2013.11.016

54. Mohd Suki, N, and Mohd Suki, N. Does Religion Influence Consumers' green Food Consumption? Some Insights from Malaysia. J Consumer Marketing (2015) 32(7):551-63. doi:10.1108/JCM-02-2014-0877

55. Lorenz, BA-S, Hartmann, M, and Langen, N. What Makes People Leave Their Food? the Interaction of Personal and Situational Factors Leading to Plate Leftovers in Canteens. Appetite (2017) 116:45-56. doi:10.1016/ j.appet.2017.04.014

56. Wu, Y, Tian, $\mathrm{X}, \mathrm{Li}, \mathrm{X}, \mathrm{Yuan}, \mathrm{H}$, and Liu, G. Characteristics, Influencing Factors, and Environmental Effects of Plate Waste at university Canteens in Beijing, China. Resour Conservation Recycling (2019) 149:151-9. doi:10.1016/ j.resconrec.2019.05.022

57. Zámková, M, and Prokop, M. Consumers Behaviour of Students when Shopping for Organic Food in the Czech Republic. Acta Univ Agric Silvic Mendelianae Brun (2013) 61(4):1191-201. doi:10.11118/actaun201361041191

58. Hamilton, K, and Hekmat, S. Organic Food and university Students: a Pilot Study. Nutr Food Sci(2018) 48(2):218-27. doi:10.1108/nfs-06-2017-0127

59. Suleiman, AA, Alboqai, OK, Kofahi, S, Aughsteen, AA, and Masri, KE. Vegetarianism Among Jordan University Students. J Biol Sci (2009) 9(3): 237-42. doi:10.3923/jbs.2009.237.242

60. Akbar, A, Ali, S, Ahmad, MA, Akbar, M, and Danish, M. Understanding the Antecedents of Organic Food Consumption in Pakistan: Moderating Role of Food Neophobia. Int J Environ Res Public Health (2019) 16(20):4043. doi:10.3390/ijerph16204043

61. Zámková, M, and Prokop, M. Consumers Behaviour of Students when Shopping for Organic Food in the Czech Republic. Acta Univ Agric Silvic Mendelianae Brun (2013) 61(4):1191-201. doi:10.11118/actaun201361041191

62. Barros, KS, Bierhals, IO, and Assunção, MCF. Vegetarianismo entre ingressantes de uma universidade pública no sul Do Brasil, 2018* Epidemiologia e Serviços de Saúde (2020) 29(4):10. doi:10.5123/s167949742020000400009

63. Pocol, CB, Marinescu, V, Amuza, A, Cadar, R-L, and Rodideal, AA. Sustainable vs. Unsustainable Food Consumption Behaviour: A Study Among Students from Romania, Bulgaria and Moldova. Sustainability (2020) 12(11):4699. doi:10.3390/su12114699

64. Forestell, CA. Flexitarian Diet and Weight Control: Healthy or Risky Eating Behavior? Front Nutr (2018) 5:5. doi:10.3389/fnut.2018.00059

65. Kawasaki, Y, Akamatsu, R, Fujiwara, Y, Omori, M, Sugawara, M, Yamazaki, Y, et al. Is Mindful Eating Sustainable and Healthy? A Focus on Nutritional Intake, Food Consumption, and Plant-Based Dietary Patterns Among Lean and normal-weight Female university Students in Japan. Eat Weight Disord (2021). doi:10.1007/s40519-020-01093-1 
66. Llanaj, E, and Hanley-Cook, GT. Adherence to Healthy and Sustainable Diets Is Not Differentiated by Cost, but rather Source of Foods Among Young Adults in Albania. Br J Nutr (2020) 126:591-9. doi:10.1017/S0007114520004390

67. Al-Domi, H, Al-Rawajfe, H, Aboyousif, F, Yaghi, S, Mashal, R, and Fakhoury, J. Determining and Addressing Food Plate Waste in a Group of Students at the University of Jordan. Pakistan J Nutr (2011) 10(9):871-8. doi:10.3923/pjn.2011.871.878

68. Lorenz, BA-S, Langen, N, Hartmann, M, and Klink-Lehmann, J. Decomposing Attitudes towards Food Leftovers. Br Food J (2018) 120(11):2498-509. doi:10.1108/bfj-08-2017-0430

69. Niggli, U. Sustainability of Organic Food Production: Challenges and Innovations. Proc Nutr Soc (2015) 74(1):83-8. doi:10.1017/ S0029665114001438

70. Gerber, PJ, Steinfeld, H, Henderson, B, Mottet, A, Opio, C, Dijkman, J, et al. Tackling Climate Change through Livestock: A Global Assessment of Emissions and Mitigation Opportunities. Rome: Food and Agriculture Organization of the United Nations (FAO) (2013). p. 139.

71. Hartmann, C, and Siegrist, M. Consumer Perception and Behaviour Regarding Sustainable Protein Consumption: A Systematic Review. Trends Food Sci Tech (2017) 61:11-25. doi:10.1016/j.tifs.2016.12.006

72. Hopwood, CJ, Bleidorn, W, Schwaba, T, and Chen, S. Health, Environmental, and Animal Rights Motives for Vegetarian Eating. PLOS ONE (2020) 15(4): e0230609. doi:10.1371/journal.pone.0230609

73. Vainio, A, Niva, M, Jallinoja, P, and Latvala, T. From Beef to Beans: Eating Motives and the Replacement of Animal Proteins with Plant Proteins Among Finnish Consumers. Appetite (2016) 106:92-100. doi:10.1016/j.appet.2016.03.002

74. Mertens, E, van't Veer, P, Hiddink, GJ, Steijns, JM, and Kuijsten, A. Operationalising the Health Aspects of Sustainable Diets: a Review. Public Health Nutr (2017) 20(4):739-57. doi:10.1017/S1368980016002664

75. Xu, C, Demir-Kaymaz, Y, Hartmann, C, Menozzi, M, and Siegrist, M. The Comparability of Consumers' Behavior in Virtual Reality and Real Life: A Validation Study of Virtual Reality Based on a Ranking Task. Food Qual Preference (2021) 87:104071. doi:10.1016/j.foodqual.2020.104071

76. Šedová, I, Slovák, L', and Ježková, I. Coping with Unpleasant Knowledge: Meat Eating Among Students of Environmental Studies. Appetite () 107:415-24. doi:10.1016/j.appet.2016.08.102

77. Larson, N, Laska, MN, and Neumark-Sztainer, D. Do young Adults Value Sustainable Diet Practices? Continuity in Values from Adolescence to Adulthood and Linkages to Dietary Behaviour. Public Health Nutr (2019) 22(14):2598-608. doi:10.1017/S136898001900096X

78. Buttlar, B, and Walther, E. Measuring the Meat Paradox: How Ambivalence towards Meat Influences Moral Disengagement. Appetite (2018) 128:152-8. doi:10.1016/j.appet.2018.06.011

79. Silva, E, Klink, J, McKinney, E, Price, J, Deming, P, Rivedal, H, et al. Attitudes of Dining Customers towards Sustainability-Related Food Values at a Public University Campus. Renew Agric Food Syst (2020) 35(3):221-6. doi:10.1017/ s1742170519000036

80. Migliorini, P, Wezel, A, Veromann, E, Strassner, C, Średnicka-Tober, D, Kahl, J, et al. Students' Knowledge and Expectations about Sustainable Food Systems in Higher Education. Int J Sustainability Higher Edu (2020) 21(6):1087-110. doi:10.1108/ijshe-12-2019-0356

81. Lucius, RE. Muslim Millennials and Cultured Meat Consumption: An Exploratory Elicitation Study. Diss Abstr Int Sect Humanit Soc Sci (2020) 81(9-A).

82. Krispenz, A, and Bertrams, A. Correlates of the Intention to Reduce Meat Consumption. Sustainability (2020) 12(11):4774. doi:10.3390/su12114774

83. Nemeth, N, Rudnak, I, Ymeri, P, and Fogarassy, C. The Role of Cultural Factors in Sustainable Food Consumption-An Investigation of the Consumption Habits Among International Students in Hungary. Sustainability (2019) 11(11):3052. doi:10.3390/su11113052

84. Yadav, R. Altruistic or Egoistic: Which Value Promotes Organic Food Consumption Among Young Consumers? A Study in the Context of a Developing Nation. J Retailing Consumer Serv (2016) 33:92-7. doi:10.1016/ j.jretconser.2016.08.008

85. Tamburro, M, Ripabelli, G, Forleo, MB, and Sammarco, ML. Dietary Behaviours and Awareness of Seasonal Food Among College Students in central Italy. Ital J Food Sci (2017) 29(4):667-80.

86. Bianchi, F, Garnett, E, Dorsel, C, Aveyard, P, and Jebb, SA. Restructuring Physical Micro-environments to Reduce the Demand for Meat: a Systematic Review and Qualitative Comparative Analysis. Lancet Planet Health (2018) 2(9):e384-e397. doi:10.1016/S2542-5196(18)30188-8

87. Bianchi, F, Dorsel, C, Garnett, E, Aveyard, P, and Jebb, SA. Interventions Targeting Conscious Determinants of Human Behaviour to Reduce the Demand for Meat: a Systematic Review with Qualitative Comparative Analysis. Int J Behav Nutr Phys Act (2018) 15(1):102. doi:10.1186/s12966-018-0729-6

88. Graça, J, Godinho, CA, and Truninger, M. Reducing Meat Consumption and Following Plant-Based Diets: Current Evidence and Future Directions to Inform Integrated Transitions. Trends Food Sci Tech (2019) 91:380-90. doi:10.1016/j.tifs.2019.07.046

89. Bicchieri, C. Norms in the Wild: How to Diagnose, Measure, and Change Social Norms. Oxford: Oxford University Press (2017). p. 239.

90. Yamin, P, Fei, M, Lahlou, S, and Levy, S. Using Social Norms to Change Behavior and Increase Sustainability in the Real World: a Systematic Review of the Literature. Sustainability (2019) 11(20):5847. doi:10.3390/ su11205847

91. Folke, C, Biggs, R, Norström, AV, Reyers, B, and Rockström, J. Socialecological Resilience and Biosphere-Based Sustainability Science. Ecol Soc (2016) 21(3):41. doi:10.5751/ES-08748-210341

Copyright (c) 2021 Aguirre Sánchez, Roa-Díaz, Gamba, Grisotto, Moreno Londoño, Mantilla-Uribe, Rincón Méndez, Ballesteros, Kopp-Heim, Minder, Suggs and Franco. This is an open-access article distributed under the terms of the Creative Commons Attribution License (CC BY). The use, distribution or reproduction in other forums is permitted, provided the original author(s) and the copyright owner(s) are credited and that the original publication in this journal is cited, in accordance with accepted academic practice. No use, distribution or reproduction is permitted which does not comply with these terms. 